\title{
Políticas de control de la influenza en Chile
}

\author{
Pedro Astudillo O.
}

\section{Policies for influenza control in Chile}

Influenza control is based in two main components: a surveillance system and vaccination. In both aspects Chile has conquered high internacional standards and can exhibit the best results in the Region, obtaining a significant reduction in mortality attributable to influenza and pneumonia as vaccine coverage has increased over $11 \%$ of the total population. Pandemic influenza menace is permanent and obliges national authorities to prepare special strategies to face it.

Key words: influenza; epidemiology; prevention.

Palabras claves: influenza; epidemiología; prevención.

\section{Introducción}

$\mathrm{L}$ a influenza es producida por un virus de la familia Orthomyxoviridae, y del cual existen tres tipos: influenza A, que además de afectar al hombre puede infectar a un gran número de aves y animales; influenza $\mathrm{B}$, que provoca enfermedad sólo en humanos; e influenza $\mathrm{C}$, mucho menos frecuente, que no es capaz de provocar epidemias ni pandemias, aunque puede afectar a humanos y cerdos. A su vez, el virus influenza A tiene distintos subtipos, dados por las glicoproteínas de su superficie, que son la hemaglutinina (HA) y la neuraminidasa (NA). Hay 15 subtipos de HA y 9 de NA, pero sólo los subtipos de HA 1, 2 y 3 y los de NA 1 y 2 son los que han afectado al hombre.

El cuadro clínico característico de la influenza, descrito por Hipócrates, 412 años AC, se caracteriza por fiebre de varios días de duración, cefalea, mialgias, artalgias, decaimiento, tos seca, odinofagia y fotofobia. El examen físico no es específico y los pacientes mejoran en 2 a 7 días pero el decaimiento y la tos pueden durar más de 2 semanas. En lactantes, es clínicamente indistinguible del cuadro clínico causado por otros virus respiratorios, y en algunos casos puede agregarse otitis.

La influenza se transmite de persona a persona mediante aerosoles de saliva que se generan al toser o al estornudar y son inhalados hacia la vía aérea superior de terceras personas. El periodo de mayor transmisión son las primeras 48 horas de infección, aún cuando el paciente esté asintomático. La excreción viral se hace negativa entre el sexto y octavo día desde inicio de los síntomas, pero puede ser más larga en lactantes e inmunocomprometidos.

\section{Estrategias de control}

El control de la influenza tiene dos pilares fundamentales, como son la vigilancia epidemiológica y la vacunación. Los antivirales tienen un rol bastante limitado desde el punto de vista epidemiológico.

Vigilancia epidemiológica. La vigilancia de la influenza en nuestro país forma parte del sistema de vigilancia epidemiológica del Programa IRA, contribuyendo a gestionar los Programas Nacionales de IRA y ERA y la Campaña de Invierno. La identificación de los virus circulantes es realizada en el Laboratorio de Virología del Instituto de Salud Pública (ISP), con muestras procedentes de todo el país; la genotipificación de las cepas se realiza en el CDC de E.U.A. con muestras enviadas por el ISP. La notificación de casos se registra en el Departamento de Epidemiología del MINSAL, dándose cuenta semanalmente de la situación de todo el país en cuanto al diagnóstico clínico de casos. Habitualmente, el pico de consultas ambulatorias en Servicios de Emergencia y consultorios de Atención Primaria coincide exactamente con el máximo de notificación de casos y de identificación de virus influenza. Además, Chile forma parte del sistema mundial de vigilancia de influenza de OMS (FluNet). Según este sistema, OMS hace dos recomendaciones anuales con la composición que debe tener la vacuna para cada hemisferio, logrando una predicción de la cepa circulante en más del $90 \%$ de los casos.

Vacunación. La recomendación para la presente temporada (2005) del hemisferio sur incluyó las cepas A/Wellington/1/2004 (H3N2), A/New Caledonia/20/ 1999 (H1N1) y B/Shangai/361/2002 like, cambiando la primera por A/California/7/2004 (H3N2) y conservando las otras dos en la recomendación 2005-06 para el
Unidad de Salud Respiratoria, Ministerio de Salud

Recibido: 10-08-05 Aceptado: 17-08-05

Correspondencia a: Pedro Astudillo Olivares pastudillo@minsal.cl 
hemisferio norte. En Chile se usa sólo vacunas inactivadas, de tipo particulada (fragmentos del virus, split vaccines en inglés) o subunidades (antígenos purificados). Otros tipos de vacunas (nasales que contienen virus atenuado, virosomales o elaboradas con genética reversa) no están disponibles en nuestro país. Cada año, el Ministerio de Salud realiza una campaña de vacunación anti-influenza, que tiene por objetivos: disminuir la aparición de casos de influenza; proteger a los grupos de riesgo de las complicaciones graves de la influenza; y disminuir la letalidad en la población de 65 años y más. Los grupos de riesgo que se deben vacunar son: adultos de 65 años y más, personas de cualquier edad portadoras de algunas enfermedades crónicas, personal del Sector Público de Salud, mujeres embarazadas en $2^{\circ}$ y $3^{\text {er }}$ trimestre de gestación durante la "temporada" de influenza y niños de 6 a 23 meses. Las enfermedades crónicas que se deben considerar para la vacuna son: enfermedad pulmonar obstructiva crónica, asma, enfisema pulmonar, tuberculosis pulmonar, neumoconiosis, fibrosis quística, displasia broncopulmonar, diabetes insulina-dependiente, diabetes no insulina-dependiente que han requerido hospitalización el año anterior, enfermedad coronaria isquémica, enfermedad cardiaca crónica, insuficiencia renal crónica en hemodiálisis, tratamiento con fármacos antineoplásicos o inmunosupresores y discrasias sanguíneas severas.

Terapia especifica. Existen dos tipos de antivirales: inhibidores de la proteína M2, como son la amantadina y la rimandadina, útiles sólo en influenza $\mathrm{A}$, e inhibidores de neuraminidasa, que actúan sobre influenza A y B, es el caso de oseltamivir; que se usa por vía oral desde el año de edad y zanamivir, indicado por vía inhalatoria, pero no disponible en Chile. Ambos tipos de antivirales son útiles en reducir la duración de los síntomas y la excreción viral si se usan como preventivos o al inicio de los síntomas, siendo oseltamivir el antiviral de elección en la eventualidad de pandemia. Los antivirales presentan utilidad clínica, pero su rol epidemiológico es limitado.

\section{Resultados}

Chile tiene una cobertura de vacunación superior al resto de los países latinoamericanos y a muchos países con más desarrollo, habiendo alcanzado el año
2002 a 115 dosis/1000 habitantes (aproximadamente $11 \%$ de la población total). El aumento de dosis a contar de 1997 y luego a todos los grupos de riesgo a contar del año 2000 ha permitido reducir significativamente la mortalidad por influenza y por neumonía, convirtiendo a la vacunación anti-influenza en una de las intervenciones sanitarias más eficientes y costoefectivas.

\section{La amenaza de pandemia}

El virus influenza puede experimentar dos tipos de cambios antigénicos. El llamado cambio antigénico menor, o antigenic drift, que consiste en una mutación puntual de los genes que codifican la HA, determinando una evasión de respuesta inmune, y potenciando la aparición de una epidemia. El cambio antigénico mayor, o antigenic shift, es consecuencia de la recombinación genética entre virus influenza de diferentes especies, lo que produce un reordenamiento del genoma, generándose un nuevo subtipo viral, y dando como resultado una posible pandemia. En los últimos 10 años se han producido varias mutaciones de tipo zoonosis amenazantes de pandemia. Son destacables por su número en humanos las cepas de origen aviar: A(H7N7) con 89 casos, que apareció en Holanda en el 2003, con un cuadro clínico caracterizado preferentemente por conjuntivitis, aunque provocó 1 fallecido, y la cepa $\mathrm{A}(\mathrm{H} 5 \mathrm{~N} 1)$, con presencia en el sudeste de Asia desde el año 2003, de la que se han reportado hasta el 14 de diciembre 2005, 138 casos en humanos con 71 fallecidos, es decir, con una alta letalidad $(51,4 \%)$.

\section{Resumen}

El control de la influenza se logra sobre la base de dos componentes principales: la vigilancia epidemiológica y la vacunación. En ambos aspectos, Chile tiene un alto posicionamiento en el mundo y exhibe las mejores cifras de la región, logrando una reducción de la mortalidad por influenza y neumonía en la medida del aumento en la cobertura de vacunación, la que en la actualidad alcanza a $11 \%$ de la población. La amenaza de una pandemia es permanente y obliga a los países a tener preparadas sus estrategias especiales de enfrentamiento.

\section{Referencias}

1.- Jofré L, Perret C, Dabanch J, Abarca K, Olivares R, Luchinger V, et al. Influenza: the reemergence of an ancient disease and its risk of pandemia. Rev Chilena Infectol 2005; 22 (1): 75-88

2.- CDC. Prevention and control of influenza:
Recommendations of the Advisory Committee on Immunization Practices (ACIP). Morb Mortal Wkly Rep 2005; 54 (RR08): $1-40$

3.- http://www.cdc.gov/flu/

4.- Nicholson KG, Wood JM, Zambon M: Influenza. Lancet 2003; 362 (9397): 173345 .
5.- Quach C, Piche-Walker L, Platt R, Moore D: Risk factors associated with severe influenza infections in childhood: implication for vaccine strategy. Pediatrics 2003; 112: e197-201

6.- Webby RJ, Webster RG: Are we ready for pandemic influenza? Science 2003; 302 (5650): 1519-22 